\title{
De $\ddot{\omega} \sigma \tau \in(\dot{w} \varsigma)$ particulae usu egerunt:
}

Seume H., de sententiis consecutiviş Graecis. Göttingen 1883.

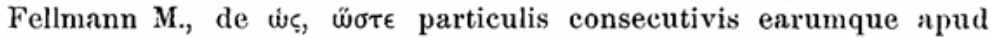
tragicos Graecorum poëtas vi et usu. Breslau 1883.

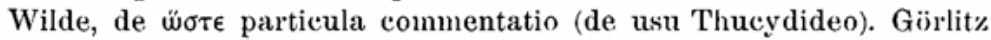
1861.

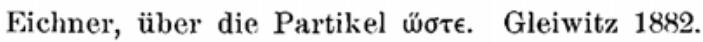

Walther O., über ws bei Herodot. Hameln 1887.

Thomas G., de particulae ws usu Herodoteo. Leipzig 1888.

\section{Conspectus rerum tractatarum.}

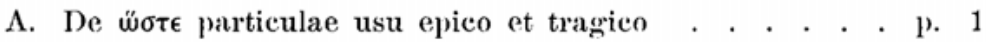

B. De $\ddot{\sigma \tau \epsilon}(\dot{w} \varsigma)$ particulae usu Herodoteo, Thucydideo, Xenophonteo

I. De $\tilde{\sigma} \sigma \tau \epsilon$ parti

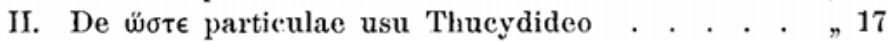

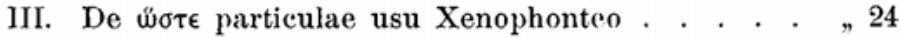

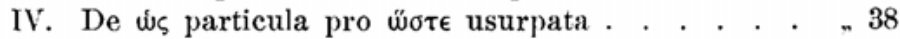

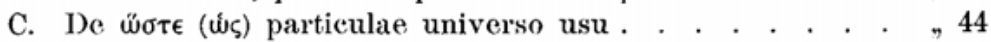


